\title{
Maritime routing and speed optimization with emission control areas
}

\author{
Fagerholt, Kjetil; Gausel, Nora T.; Rakke, Jørgen G.; Psaraftis, Harilaos N.
}

Published in:

Transportation Research. Part C: Emerging Technologies

Link to article, DOI:

10.1016/j.trc.2014.12.010

Publication date:

2015

Document Version

Peer reviewed version

Link back to DTU Orbit

Citation (APA):

Fagerholt, K., Gausel, N. T., Rakke, J. G., \& Psaraftis, H. N. (2015). Maritime routing and speed optimization with emission control areas. Transportation Research. Part C: Emerging Technologies, 52, 57-73.

https://doi.org/10.1016/j.trc.2014.12.010

\section{General rights}

Copyright and moral rights for the publications made accessible in the public portal are retained by the authors and/or other copyright owners and it is a condition of accessing publications that users recognise and abide by the legal requirements associated with these rights.

- Users may download and print one copy of any publication from the public portal for the purpose of private study or research.

- You may not further distribute the material or use it for any profit-making activity or commercial gain

- You may freely distribute the URL identifying the publication in the public portal 


\title{
Maritime routing and speed optimization with emission control areas ${ }^{1}$
}

\author{
Kjetil Fagerholt ${ }^{1 *}$, Nora T Gausel ${ }^{1}$, Jørgen G Rakke ${ }^{2}$ and Harilaos N \\ Psaraftis $^{3}$ \\ ${ }^{1}$ Department of Industrial Economics and Technology Management, Norwegian University of \\ Science and Technology, Trondheim, Norway \\ ${ }^{2}$ Norwegian Marine Technology Research Institute (MARINTEK), Trondheim, Norway \\ ${ }^{3}$ Department of Transport, Technical University of Denmark, Lyngby, Denmark
}

Date: 19th of December, 2014

\begin{abstract}
Strict limits on the maximum sulphur content in fuel used by ships have recently been imposed in some Emission Control Areas (ECAs). In order to comply with these regulations many ship operators will switch to more expensive low-sulphur fuel when sailing inside ECAs. Since they are concerned about minimizing their costs, it is likely that speed and routing decisions will change because of this. In this paper, we develop an optimization model to be applied by ship operators for determining sailing paths and speeds that minimize operating costs for a ship along a given sequence of ports. We perform a computational study on a number of realistic shipping routes in order to evaluate possible impacts on sailing paths and speeds, and hence fuel consumption and costs, from the ECA regulations. Moreover, the aim is to examine the implications for the society with regards to environmental effects. Comparisons of cases show that a likely effect of the regulations is that ship operators will often choose to sail longer distances to avoid sailing time within ECAs. Another effect is that they will sail at lower speeds within and higher speeds outside the ECAs in order to use less of the more expensive fuel. On some shipping routes, this might give a considerable increase in the total amount of fuel consumed and the $\mathrm{CO}_{2}$ emissions.
\end{abstract}

Keywords: Maritime transportation, routing, speed optimization, emissions

\footnotetext{
${ }^{1}$ Transportation Research Part C, in press.
} 
* Corresponding Author: Phone: +47 975684 97, Email: kjetil.fagerholt@iot.ntnu.no

\section{INTRODUCTION}

Ocean-going vessels carry more than 90 per cent of global trade (IMO, 2014), and shipping is considered environmentally efficient. However, there are still significant emissions associated with the operations. Emissions from the shipping industry are closely correlated to its consumption of fuel, which has been estimated to be between 279 and 400 million tons (Cullinane and Bergqvist, 2014). Since ships move between different jurisdictions, there is a need for international regulations. The International Maritime Organization (IMO), a specialized agency of the United Nations, is responsible for, among other things, regulations on the safety and security of shipping and the prevention of maritime pollution by ships. MARPOL is the main international convention concerning prevention of pollution of the marine environment by ships, and in 1997 the convention was updated with Annex VI, which more specifically considers air pollution from ships and sets limits on the emissions of both $\mathrm{NO}_{\mathrm{x}}$ and $\mathrm{SO}_{\mathrm{x}}$ from ship exhausts. In 2008 the IMO agreed on the latest version of Annex VI setting a global limit on the sulphur content of a ship's fuel to $3.50 \%$ (from 2012) followed by a reduction to $0.50 \%$ from 2020 (though subject to a review to be completed by 2018 which may conclude to prolong this stricter requirement to 2025).

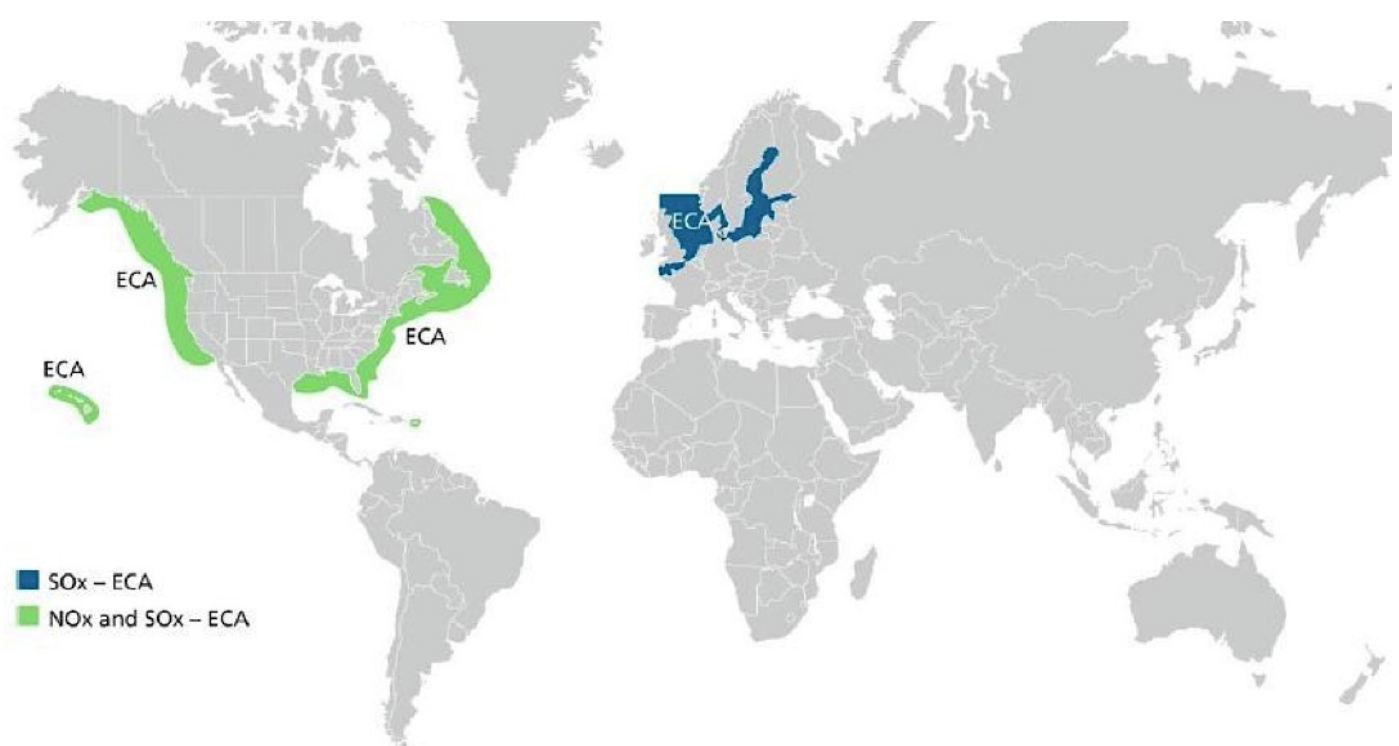

Figure 1: Map over current Emission Control Areas

Four Emission Control Areas (ECAs) have also been defined by MARPOL, as shown in Figure 1. These are the Baltic Sea, the North Sea and English Channel, and the North American and the US Caribbean coasts. Within these ECAs there is even more stringent control of the sulphur emissions with a limit of $0.1 \%$ sulphur content in the ship's fuel from January 1, 2015. The North American and US Caribbean ECAs also 
regulate $\mathrm{NO}_{\mathrm{x}}$ emissions. In addition, the $\mathrm{EU}$ has adopted legislation transposing the IMO regulations into EU law, the latest version of which is Directive 2012/33/EU (also known as the sulphur directive). The sulphur directive is more stringent than MARPOL Annex VI, as irrespective of the outcome of the proposed IMO review in 2018 , a reduction to a cap of $0.50 \%$ sulphur content will be unilaterally implemented in the EU on 1 January 2020 and also all passenger ships in the EU's non-ECA waters will have a maximum $1.5 \%$ sulphur content until that time.

There are several ways shipping companies can achieve compliance with the ECA sulphur regulations. The one we will focus on in this paper is fuel switching, which is a straightforward compliance alternative for ships that operate both within and outside ECAs. This means using a low sulphur fuel, such as marine gas oil (MGO) within ECAs, while the more commonly used fuel type, heavy fuel oil (HFO), is used outside. Switching fuel is a necessity for deep sea vessels that cross in and out of ECAs, so these ships need to keep two fuel tanks, one for HFO and another for MGO. Technically it is easy to do (only caution is in the fuel pump and in the fuel switch phase, as HFO is preheated and MGO is cold). The corresponding investment costs are minor as compared to solutions such as scrubbers (see below), which permit a ship to burn HFO within ECAs. But these solutions are not cost effective for deep sea vessels as the portion of time they spend in ECAs is low.

The second option is to install a scrubber, which is a filtering/cleaning system to remove the sulphur from the exhaust. This permits the ship to use HFO in ECAs. Such solutions are used by some short sea ferry operators, such as for instance DFDS Seaways, which has embarked upon a massive scrubber installation program, with an investment cost of about 125 million USD for 21 ships.

The third alternative involves using liquefied natural gas (LNG) as fuel. This reduces emissions of sulphur and potentially many other substances such as nitrogen oxides. This involves retrofitting the ship so that it can store and burn LNG, and also making sure there are adequate shoreside LNG supply facilities at the ports in which the ship will refuel.

It is clear that the latter two options both require significant investment costs, especially the LNG option which also involves land-based infrastructure.

Compliance with ECA regulations has received significant attention lately, both from shipping companies and from the research community. Schinas and Stefanakos (2012) propose a stochastic programming model for determining the mix of a fleet of ships operating in ECAs. The recent special issue in Transportation Research Part D 
(Cullinane and Bergqvist, 2014) focuses more on the technical options to comply with the ECA regulations. Jiang et al. (2014) perform an economic analysis to compare scrubbers and fuel switching. Their analysis shows that which of these two options that is preferable depends on the price spread between MGO and HFO. Yang et al. (2012) assess all three alternatives according to a number of criteria, such as capital and operational costs, operational difficulty and maintenance requirement. Findings show that fuel switching is preferred for $\mathrm{SO}_{\mathrm{x}}$ control, while scrubbers may become more important with stricter future limits. Brynolf et al. (2013), and Balland et al. (2012; 2013) also analyze $\mathrm{SO}_{\mathrm{x}}$ compliance in combination with $\mathrm{NO}_{\mathrm{x}}$ abatement.

Fuel costs have become an important cost item in shipping, sometimes accounting for more than $50 \%$ of the total operational costs. Low-sulphur fuel is substantially more expensive than normal bunker fuel, and the new ECA regulations will impact international shipping in several ways. For instance, there is little or no room within short-sea shipping companies' current margins to absorb such additional cost and thus significant freight rate increases must be expected. Unlike its deep-sea counterpart, in short-sea shipping such a freight rate increase may induce shippers to use land-based alternatives (mainly road). A reverse shift of cargo would go against the EU policy to shift traffic from land to sea to reduce congestion, and might ultimately (under certain circumstances) increase the overall level of $\mathrm{CO}_{2}$ emissions along the entire supply chain. This problem is already a serious source of concern not only to Ro-Ro operators in the Baltic and North Sea, that have or are contemplating shutting down some routes as unprofitable (operators such as DFDS and Stena have already shut down some of their routes), but also to manufacturing, mining and forest industries in the area. The fear is that many of these industries may be forced to relocate because of the side-effects of such operational and regulatory changes. Such loss of business might force the marginally viable ship operators and ports out of business, channeling even more cargoes towards land-based modes. The special issue of Transportation Research Part D on ECAs provides more light on this issue.

Another possible ECA side-effect, to our knowledge not yet studied, concerns speed and routing decisions. Speed is a key determinant of fuel costs, as fuel consumption per time unit is approximately proportional to the third power of speed (Psaraftis and Kontovas, 2013). Shipping companies that operate both within and outside ECAs are, due to the different costs of the fuels used, facing different speed decisions in each area. A possible consequence of the restrictions is that ships will sail at a lower speed within ECAs where fuel is more expensive and speed up outside to compensate for the longer sailing time. It can be shown (see Psaraftis and Kontovas (2009) and Doudnikoff and Lacoste (2014)) that if the ship speeds up outside the ECA to make up for lost time within the ECA, total fuel consumption, and hence $\mathrm{CO}_{2}$ emissions, will actually increase somewhat. 
Besides speed, the ECA regulations may also affect the routing of ships. Repositioning of sailing legs could lead to lower fuel costs if larger parts of the legs were moved outside ECAs, but there are several trade-offs to recognize due to the relations between distance, speed and costs. Key questions that this paper studies are if and how optimal speed and routing decisions change when considering ECA regulations, as well as what are the consequences of these decisions for the global environment. It should be noted that in this paper, routing refers to determining the sailing path across the sea between ports, and not sequencing of nodes or port calls. To our knowledge, the possible effect of ECA regulations on the routing of ships (or on combined speed and routing decisions) has not been examined thus far in the literature.

The objective of this paper is two-fold. First, we develop an optimization model to be applied by ship operators for determining optimal routing and sailing speeds for a ship along a given sequence of ports, where some of the sailing is within ECAs. The objective is to minimize the fuel costs. We consider the sulphur content regulations and fuel switch as means to comply with these. Furthermore, we perform a computational study on a number of realistic shipping routes in order to evaluate possible impacts on fuel consumption and costs from the speed and routing decisions resulting from the ECA regulations. Moreover, the aim is to consider the bigger picture and examine the implications for the society with regards to environmental effects. Comparisons of cases could allow informed predictions concerning regional and global outcomes of the sulphur restrictions.

Section 2 gives a thorough description of the problem considered, including a mathematical formulation of the problem. The formulation is made from a ship operator's point of view, i.e. determining optimal speeds and sailing paths along given geographical sailing routes. Section 3 defines the cases and shipping routes we are analyzing, as well as some assumptions made, while Section 4 presents the results. Finally, concluding remarks are given in Section 5.

\section{Problem description AND MATHEMATICAL FORMULATION}

In this section we give a formal description, including a mathematical formulation, of the problem we are considering. Some terms used in the paper are defined in Section 2.1, while Section 2.2 describes the modeling assumptions. The mathematical formulation is provided in Section 2.3.

\subsection{Definitions}

In order to give a precise problem definition, we need to define and explain some 
terms that are used in the following. Route, as shown in Figure 2 a), refers to a given sequence of port calls. A route consists of sailing legs between the ports along the route, which is used to describe the sailing between two ports. There may be several alternative paths across the sea between any two ports, which can be referred to as alternative leg options, see Figure 2 b). Typically, one leg option may have a somewhat longer distance than another, but may still be an interesting option to use as it may have a shorter distance within the ECA where the ship burns more expensive fuel. A given leg will consist of one or more stretches, as shown in Figure 2 c). A stretch ends when the leg enters a new zone, that is, enters or leaves an ECA, or when the ship arrives at a port.

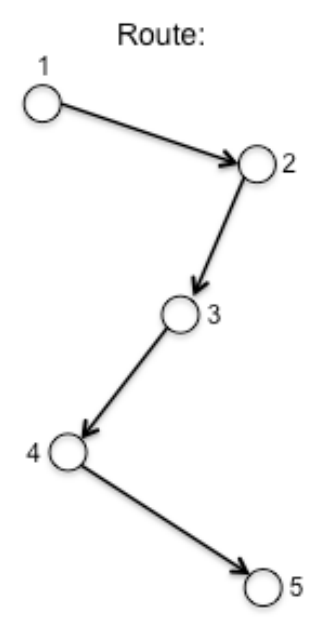

a)

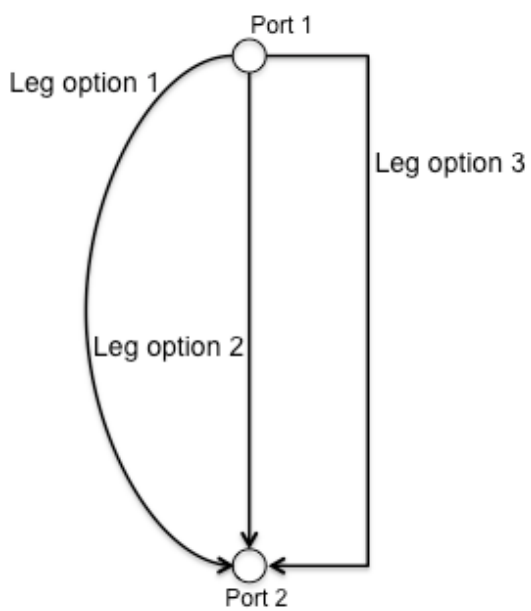

b)

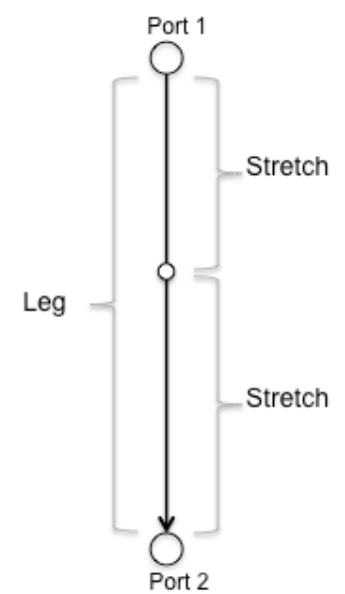

c)

Figure 2: Route (a), alternative leg options (b), and stretches (c)

There can for most practical purposes be up to three stretches within a leg, occurring if the ship leaves a port within an ECA, sails out of it and returns to an ECA zone to arrive at the next port in the route. In principle, the number of stretches in a leg can be higher than three, although one such leg is unlikely to appear in actual route plans.

\subsection{Modeling assumptions}

We consider the speed optimization and routing problem for a single vessel. As mentioned, in this paper when we use the term routing, it does not deal with determining the sequence of ports, as this is considered fixed and given, but rather the determination of which leg options to use between the ports (i.e. the sailing path across the sea). Furthermore, it is assumed that the ships comply with the ECA regulations through fuel switching, by using MGO as fuel within ECAs and HFO elsewhere. Some time is usually required to perform the fuel switch, but since this time is usually less than one hour, it is disregarded in the following. Assumptions regarding the modeling of the problem are given in the following paragraphs. 
In the following, we assume that a time window for when a sailing may start from each port along the route exists. These time windows can be adjusted to represent different situations for various shipping segments and companies. Service time in port is not considered since it is independent of the decisions in the model, and the time windows are correspondingly given based on this assumption. There may be some waiting time at a port, occurring if the lower limit of the time window starts later than the arrival time at the respective port.

As mentioned in the introduction, the speed consumption per time unit is often approximated by a cubic function of speed, giving a quadratic consumption function per distance unit. However, shipping companies often have data for fuel consumption for a number of discrete speeds instead of a function, as illustrated in Figure 3. This is also the case for the shipping company that has provided some of the data used in our computational study. We therefore use fuel consumption data for different speed points and assume linear combinations of these points to give an approximation of the consumption between these speeds. This also gives a similar discretization and interpolation of the time - speed relation. This is discussed in detail by Andersson et al. (2015), which use this approach for solving a fleet deployment problem with speed optimization. 


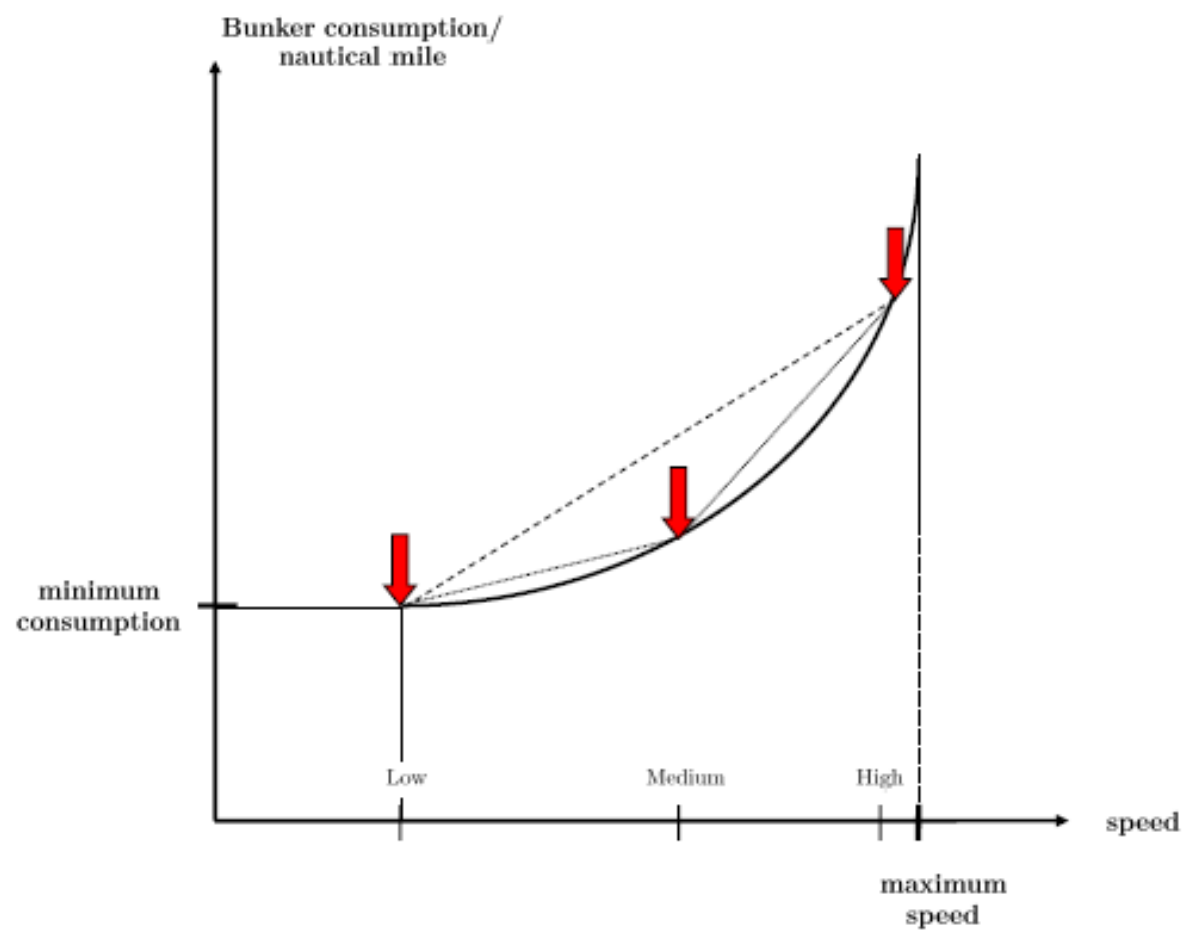

Figure 3: Piecewise linearization of the convex fuel consumption function (Andersson et al., 2015)

A ship has for all practical purposes a lower speed limit, below which the engine might stall or the fuel consumption becomes non-optimal, and an upper speed limit depending on the ship's capabilities (Psaraftis and Kontovas, 2013). The optimal speed along the route may vary between the sailing legs due to the time window constraints at the ports along the route. Furthermore, even within a leg the speed may vary along the stretches due the different prices of fuel types that are used due to the ECA regulations. As seen from previous research on the topic (e.g. Wang et al., 2013; Doudnikoff and Lacoste, 2014; Norstad et al., 2011; Hvattum et al., 2013), the speed on any single stretch will be constant. This can be shown through the fuel consumption curve characteristics.

In the analyses presented in this paper, we only minimize fuel costs, although other cost components, such as the time charter costs, could be included. The reason for doing so is that fuel costs represent a major cost component in most shipping operations. Besides, other cost factors could vary considerably from the state of the market and between shipping segments. Therefore, in order to demonstrate the effects from the introduction of the ECAs on speed and routing decisions, as well as on fuel consumption and environmental emissions, we have chosen to leave these more random effects out from the analysis. Fuel consumed by auxiliary machinery in ports is disregarded since it is independent of speed and routing decisions. 


\subsection{Mathematical model}

The mathematical model presented in the following aims at determining the optimal speed and choice of sailing paths across the sea, as a response to the ECA regulations. The model is developed under the assumption that ship operators will respond to the regulations in a way so as to minimize their own fuel costs.

First we need to define the notation used in the model:

\section{$\underline{\text { Sets }}$}

$J$

$R_{j}^{E C A}$

Set of sequenced sailing legs along the route

$R_{j}^{N}$

Set of alternative leg options including at least one ECA stretch for leg $j$

Set of alternative leg options including at least one non-ECA stretch

V for leg $j$

Set of discrete speed points

\section{Parameters}

$P^{E C A} \quad$ Fuel price of fuel used inside ECAs (MGO)

$P^{N} \quad$ Fuel price of fuel used outside ECAs (HFO)

$T_{j}^{M I N}, T_{j}^{M A X} \quad$ Lower and upper time limit for starting leg $j$

$T_{j r v}^{E C A} \quad$ Sailing time within ECA along leg option $r$ on leg $j$ with speed alternative $v$

$T_{j r v}^{N} \quad$ Sailing time outside ECA along leg option $r$ on leg $j$ with speed alternative $v$

$F_{j r v}^{E C A} \quad$ Fuel consumption within ECA along leg option $r$ on leg $j$ with speed alternative $v$

$F_{j r v}^{N} \quad$ Fuel consumption outside ECA along leg option $r$ on leg $j$ with speed alternative $v$, for $v \in V, j \in J$ and $r \in R_{j}$

\section{Decision variables}

$t_{j} \quad$ Start time on leg $j$

$z_{j r} \quad$ Binary variable, takes the value 1 if leg option $r$ is chosen for leg $j$, and 0 otherwise

$x_{\text {jrv }}^{E C A} \quad$ Weight of speed alternative $v$ within ECA on leg $j$ with option $r$ $x_{j r v}^{N} \quad$ Weight of speed alternative $v$ outside ECA on leg $j$ with option $r$ 
Now, the mathematical model can be formulated as follows:

$$
\min \sum_{j \in J} \sum_{r \in R_{j}^{E C A}} \sum_{v \in V} P^{E C A} F_{j r v}^{E C A} x_{j r v}^{E C A}+\sum_{j \in J} \sum_{r \in R_{j}^{N}} \sum_{v \in V} P^{N} F_{j r v}^{N} x_{j r v}^{\mathrm{N}}
$$

subject to

$t_{j} \geq t_{j-1}+\sum_{r \in R_{j}} \sum_{v \in V}\left(T_{j r v}^{E C A} x_{j r v}^{E C A}+T_{j r v}^{N} x_{j r v}^{N}\right), \quad j \in J$,

$\sum_{v \in V} x_{j r v}^{E C A}=z_{j r}$

$j \in J, r \in R_{j}^{E C A}$,

$\sum_{v \in V} x_{j r v}^{N}=z_{j r}$

$j \in J, r \in R_{j}^{N}$,

$\sum_{r \in R_{j}} z_{j r}=1$,

$j \in J$,

$T_{j}^{M I N} \leq t_{j} \leq T_{j}^{M A X}$

$j \in J$,

$z_{j r} \in\{0,1\}$,

$j \in J, r \in R_{j}$,

$x_{\text {jrv }}^{E C A} \geq 0$,

$j \in J, r \in R_{j}^{E C A}, v \in V$,

$x_{j r v}^{N} \geq 0$

$j \in J, r \in R_{j}^{N}, v \in V$.

The objective function (1) aims at minimizing the fuel cost. The two terms sum the fuel costs for sailing the ECA and non-ECA stretches chosen to sail, respectively. It should be emphasized, as illustrated in Figure 2, that each sailing leg can consist of (at least) one stretch of both types (i.e. ECA and non-ECA). Constraints (2) define the start time for each sailing leg, while constraints (3) and (4) define the relationship between the speed variables and the routing variables by stating that the sum of the speed weight variables for each leg option should equal the binary variable reflecting whether this leg option is used. The linear combinations of the speed variables $x_{j r v}^{E C A}$ and $x_{j r v}^{N}$, i.e. the left-hand-side of constraints (3) and (4), also will define the speed on the ECA and non-ECA stretch(es), respectively, on each sailing leg option $r$ for each sailing leg $j$. Constraints (5) force exactly one leg option to be chosen for each of the sailing legs in the route. Time windows on the start of each sailing leg are given by constraints (6). Binary requirements for the routing variable are imposed by constraints (7), while non-negativity for the speed variables is ensured by constraints (8) and (9). It should be noted that since minimize the fuel costs and the consumption curve is convex, there will always be (at most) two adjacent $x$ variables (of type ECA and/or non-ECA) that are non-zero for each sailing leg. This is shown in detail by Andersson et al. (2015). 
The model is primarily developed having liner shipping routes where time windows or slot times in the ports along the route are given. We use fuel cost minimization as the objective function since this cost is the most important operational cost and since the other types of operational costs (e.g. crew costs, insurance, canal tolls, port costs, etc) do not depend on the route chosen. We note here that alternative criteria can be considered by the model to adapt it to for example tramp shipping. The reduction of the freight rate (or revenue for the trip) if a longer voyage is used can also be factored into the model as an additional cost of the longer route. This could also include a penalty for late arrival, for example by adding the following term to the objective function $C\left(t_{|J|+1}-T_{|J|+1}^{M I N}\right)$, where $t_{|J|+1}$ and $T_{|J|+1}^{M I N}$ are the arrival time and earliest arrival time in the last port, respectively, and $C$ is the penalty per time unit for being later the earliest allowed time. The parameter $C$ would represent the 'time value of the ship', which again depends on the state of the market, but could probably be approximated using the ship's time charter rate. Since it is virtually impossible to find appropriate values of $C$, as they will vary so much between operations and over time, we have decided not to include this additional term in the tests shown in Section 4. We also think this would make the main focus of our paper (which is to examine the implications from the ECA regulations with regards to the environmental effects) less clear.

If one defines only one element (i.e. sailing leg option) in the sets $R_{j}^{E C A}$ and $R_{j}^{N}$ for each $j \in J$, the problem will reduce to a speed optimization problem only, similar to the problem considered by Doudnikoff and Lacoste (2014).

\section{DATA INPUT AND TEST CASES}

This section presents the data input used in our analysis. Sections 3.1 and 3.2 present the data regarding fuel prices and fuel consumption, and the sailing routes used in our analyses, respectively, while Section 3.3 describes how we have randomly generated time windows for the ports along the various sailing routes in order to resemble realistic time requirements from a number of shipping operations.

\subsection{Fuel prices and consumption}

The fuel prices vary from port to port and change constantly. For HFO, the price observed in April 2014 varied between 575-605 USD/ton, while the price of MGO ranged from 870 to 1,000 USD/ton. The fuel prices chosen as inputs to the models are based on an average of the prices in Rotterdam in Europe and Houston in the US, since a ship operating within any ECA is likely to bunker from ports on these continents. The absolute fuel prices may change, but the relationship between the 
fuel prices for fuels allowed within and outside ECAs is the determining factor for the speed and routing choices we are considering in this paper.

The input price of HFO used in the following analysis is set to 590 USD/ton for all test cases and scenarios. Each case is tested for several prices of MGO, referred to as different price scenarios, reflecting possible developments of the fuel price ratios in the future. A standard scenario analyzed for all cases is based on an MGO price of 920 USD/ton. The benchmark scenario represents the situation prior to the implementation of ECAs, where only HFO costing 590 USD/ton per ton is used everywhere. The two key scenarios regarding fuel prices are summarized in Table 1.

\begin{tabular}{lrr} 
Scenario name & \multicolumn{2}{c}{$\begin{array}{c}\text { Fuel price } \\
\text { (USD/ton) }\end{array}$} \\
& ECA & Non-ECA \\
\hline Benchmark scenario & 590 & 590 \\
Standard scenario & 920 & 590 \\
\hline
\end{tabular}

Table 1: Main fuel price scenarios

There are large differences in the fuel consumption of different ships. The model presented in Section 2 is general and can be applied to any type of vessel having non-decreasing and convex speed consumption as a function of speed. In most studies a theoretical cubic function is used to approximate the fuel consumption (per time unit) as a function of speed. However, in our study, we have instead used real data for two roll-on roll-off ships. In our data, the historically obtained fuel consumptions have been recorded for a number of discrete speed options (for each nautical mile/hour), as shown in Figure 4 . These are the real consumptions, and in between these discrete speed options, we use linear interpolation as an approximation. This gives a very good approximation of the real fuel consumption. It should be emphasized that even though we have used both ship types in our analysis, we only show the results from using ship type 1, as the results from using the fuel consumption data for ship type 2 gave very similar results. 


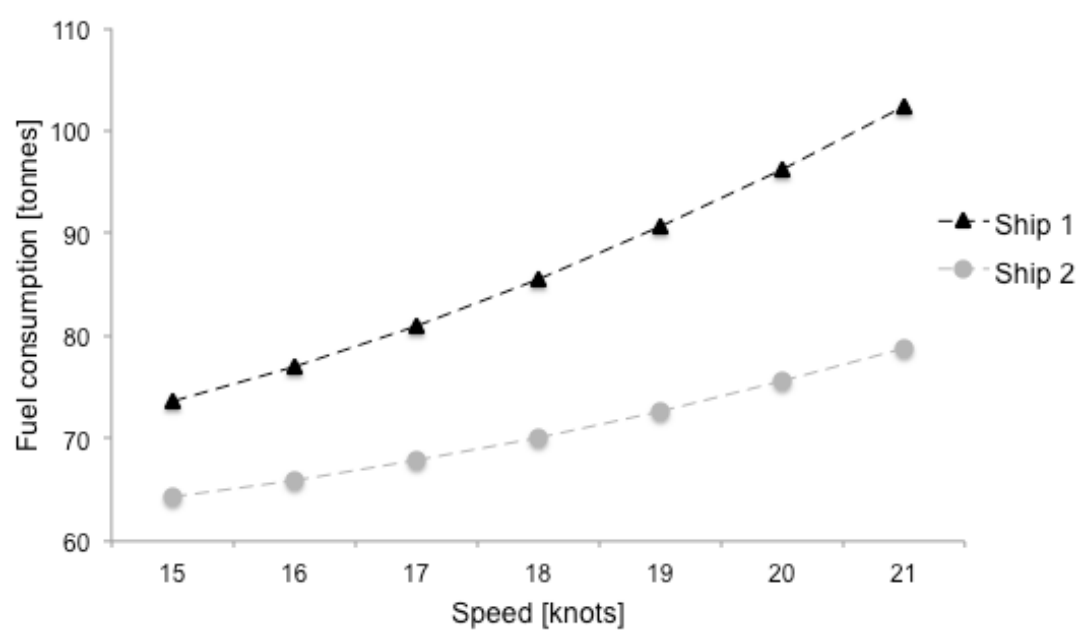

Figure 4. Fuel consumption per speed for two ship types sailing a given distance of 500 nautical miles

\subsection{Sailing routes}

The routes in the cases have been generated using Google Earth, which is a virtual globe, map and geographical information program where navigation coordinates can be plotted. The coordinates of the ECAs are given by the IMO, so the distances can be found for each area and stretch based on the specified points at sea. Table 2 lists all ports that are included in the various routes generated for our computational study, with their geographic locations. The ports in North America and Europe are numbered and plotted on the maps in Figures 5Figure and 6, respectively.

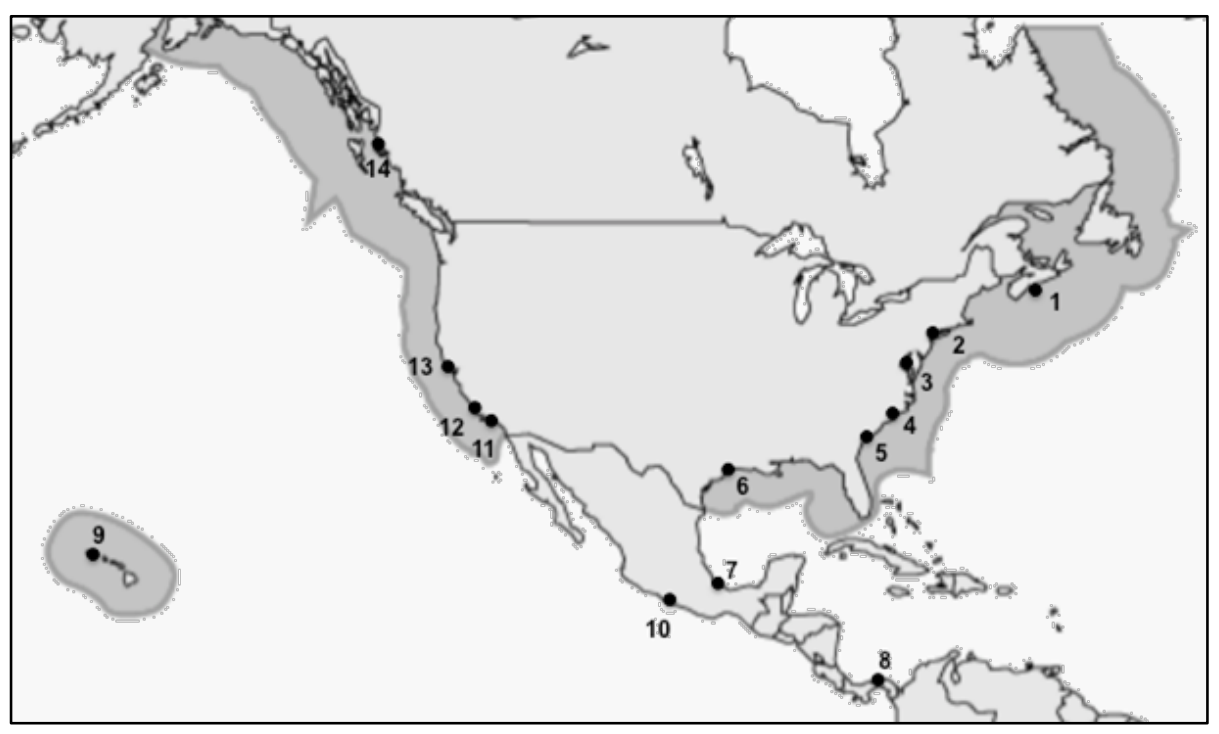

Figure 5: Map of numbered ports in North America 


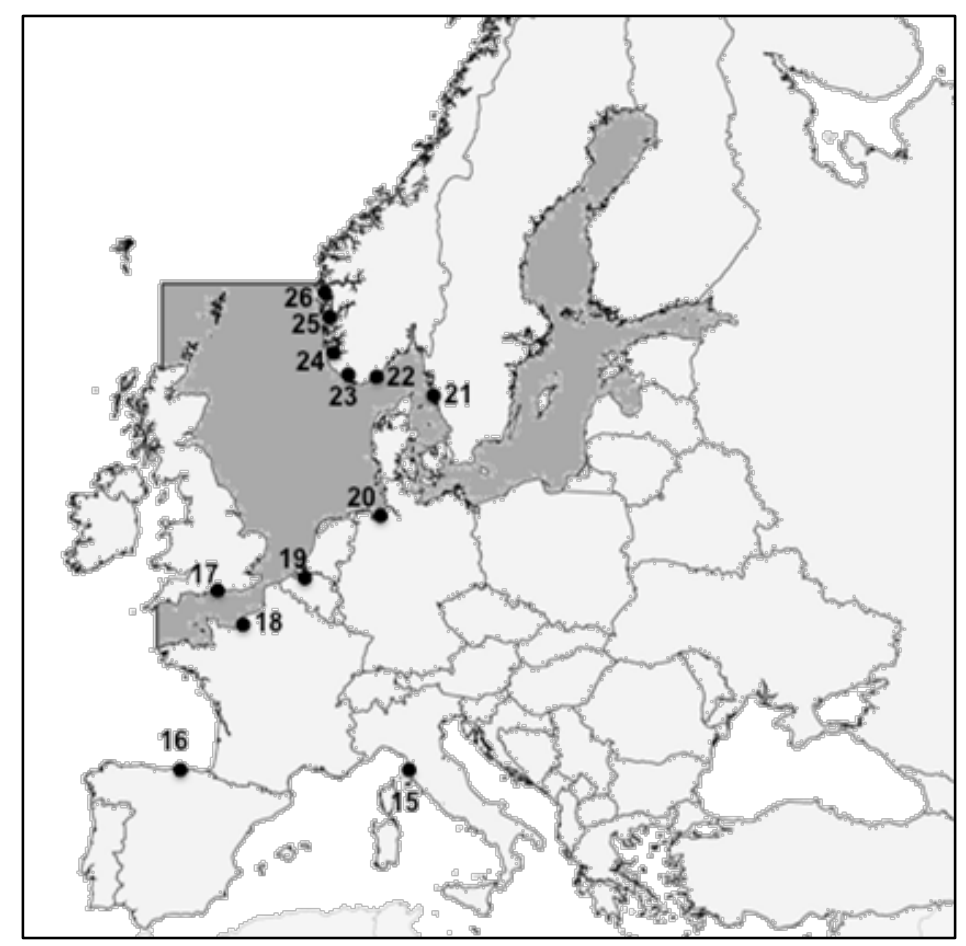

Figure 6: Map of numbered ports in Europe

\begin{tabular}{lclrrr} 
Port & No & Location & ECA & Latitude & Longitude \\
\hline $\begin{array}{l}\text { North America East } \\
\text { Halifax, Canada }\end{array}$ & 1 & Atlantic Ocean & Yes & 44.6370 & -3.5681 \\
Brunswick, Georgia, US & 5 & Atlantic Ocean & Yes & 31.1477 & -1.4974 \\
& & & & & \\
Europe & & & & & \\
Livorno, Italy & 15 & Mediterranean & No & 43.5622 & 10.2950 \\
Santander, Spain & 16 & Atlantic Ocean & No & 43.4589 & -3.8066 \\
Southampton, UK & 17 & English Channel & Yes & 50.8965 & -1.3968 \\
Le Havre, France & 18 & English Channel & Yes & 49.4900 & 0.1000 \\
Antwerp, Belgium & 19 & North Sea & Yes & 51.2700 & 4.3367 \\
Bremerhaven, Germany & 20 & North Sea & Yes & 53.5500 & 8.5833 \\
Gothenburg, Sweden & 21 & Baltic Sea & Yes & 57.7000 & 11.9333 \\
Kristiansand, Norway & 22 & North Sea & Yes & 58.1450 & 7.9990 \\
Flekkefjord, Norway & 23 & North Sea & Yes & 58.2661 & 6.6498 \\
Stavanger, Norway & 24 & North Sea & Yes & 58.9719 & 5.7365 \\
Bergen, Norway & 25 & North Sea & Yes & 60.3943 & 5.3142 \\
Florø, Norway & 26 & North Sea & Yes & 61.5999 & 5.0337
\end{tabular}

Asia/Oceania

Cilacap, Australia

29 Indian Ocean

No $\quad-7.7457 \quad 109.0183$

Table 2: Overview of ports included in the sailing routes for the computational study

Based on the ports shown in Table 2, we have generated a number of sailing routes to study. One of these routes was used to study a problem variant where the sailing 
legs along the route are given and the speed on each stretch is optimized. This variant of the problem is denoted P1. The other routes are used to study the effects from the ECA regulations on both sailing speed and routing. This problem variant is denoted P2. Several of the routes are based on real shipping routes, while some are constructed (more or less randomly) in order to test the effects of the ECA regulations. Each case is named based on the relevant problem variant, i.e. P1 or P2, and a case number, as there might be several cases for each problem variant. Table 3 below gives an overview of all sailing routes defined for the two problem variants.

\begin{tabular}{cll} 
Problem & Case & Route \\
\hline P1 & C1.1 & Gothenburg - Le Havre - Santander - Livorno \\
\hline \multirow{4}{*}{ P2 } & C2.1 & Bremerhaven - Antwerp - Halifax - Brunswick \\
\cline { 2 - 3 } & C2.2a & Kristiansand - Santander \\
& C2.2b & Flekkefjord - Santander \\
& C2.2c & Stavanger - Santander \\
& C2.2d & Bergen - Santander \\
& C2.2e & Flor $\varnothing$ - Santander \\
\cline { 2 - 3 } & C2.3 & Cilacap - Southampton \\
\hline
\end{tabular}

Table 3: Overview of case routes analyzed

As already mentioned in Section 3.1, several of the cases or sailing routes will be analyzed for many different fuel prices, referred to as price scenarios. A scenario takes the name after the case and the MGO price. A standard scenario is developed for an MGO price of 920 USD/ton. HFO has a constant price of 590 USD/ton in all scenarios. For the special benchmark scenario, the fuel price within ECAs is also 590 USD/ton since it is assumed that there are no ECA regulations and HFO can be used everywhere at sea. This scenario is included for comparison purposes to evaluate the effect of the enforced ECA regulations. The benchmark scenario of for example case C1.1 is named C1.1_590, while the standard scenario is named C1.1_920. In addition, as described in Section 3.3, several time windows are generated for each such scenario.

\subsection{Generation of time windows}

Normally, each port along a sailing route has an associated time window for when operations may start. These time windows can come from contractual agreements with customer regarding laydays for when cargoes are to be loaded or unloaded, or it can represent time slots that are agreed with port operators. Here, we use a method to randomly generate a set of realistic time windows for each sailing route considered, in order to mimic a number of shipping operations. For each sailing leg, a speed point is randomly drawn from a range of realistic speed alternatives. The sample range used is 17 and 19 knots. This corresponds to normal sailing speeds for the ships considered in our analysis. The start time at each port is based on the 
sailing time on previous legs at the reference speeds while sailing the shortest leg option, and this time is the mean value of the generated time window. The lower and upper time limits are set to a certain number of days before and after this point, defining the time window widths. Following this method, we can easily generate a number of instances with different time windows for each sailing route considered.

\section{CASE ANALYSES}

The model presented in Section 3 has been implemented and solved using the commercial optimization software Xpress-MP. The solution times for all test problems were minimal ( $<1$ second), so in the following discussion we do not report any more information regarding this.

Section 4.1 presents the results for the case for problem variant P1, C1.1, where speed is the only decision variable. Sections $4.2-4.4$ present the results for problem variant $\mathrm{P} 2$ on the cases $\mathrm{C} 2.1, \mathrm{C} 2.2$ and $\mathrm{C} 2.3$, respectively. Here the sailing path across the sea is determined in addition to the sailing speed.

\subsection{Case analysis C1.1}

In problem variant $\mathrm{P} 1$, there is a single sailing leg option available for each sailing leg, thus the only decision is the speed on the various stretches along the route. Table 4 shows the legs in the test case used for the analysis of problem P1. The route starts in Gothenburg in Sweden and sails through the North Sea and the English Channel, visiting Spain before finally ending in Livorno, Italy. Figure 7 shows a map of the route where the circles represent the ports. The total distance of the route is 2,973 nautical miles, and with a normal speed of for example 17 knots, the voyage would take approximately seven days and seven hours, port operations excluded.

\begin{tabular}{lrrr} 
Leg & \multicolumn{3}{c}{ Distance } \\
& ECA & Non-ECA & Total \\
\hline Gothenburg - Le Havre & 680 & 0 & 680 \\
Le Havre - Santander & 210 & 345 & 555 \\
Santander - Livorno & 0 & 1,738 & 1,738 \\
\hline Total distance & 890 & 2,083 & 2,973 \\
\hline
\end{tabular}

Table 4: Distances of route legs in nautical miles (C1.1) 


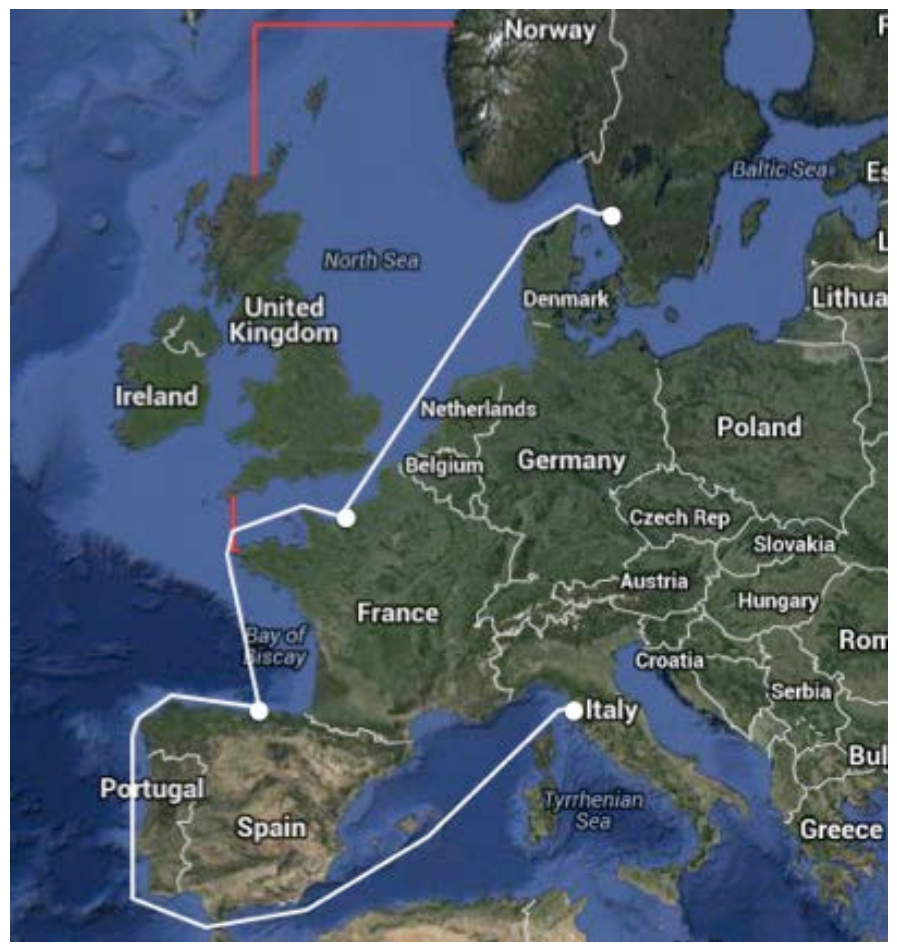

Figure 7: Map of route C1.1

We have used the model presented in Section 3 to calculate the optimal speeds along the sailing route for a number of scenarios regarding the price of MGO. Table 5 shows the resulting speeds and fuel consumption within and outside ECAs. The result for each price scenario is averaged over four different time window widths, ranging from 0.5 to 2 days, generated as presented in Section 3.3. Case scenario C1.1_590 is the benchmark which corresponds to the situation before ECA regulations were enforced and HFO could be used everywhere. For this scenario the speed is equal in both areas, although possibly with different speeds on different legs due to the presence of time windows. In addition to the standard scenario with an MGO price of 920 USD/ton, three other prices are analyzed in order to test the effect of a possible increase of MGO. For the standard scenario, with an MGO price of 920, the speed outside ECAs is $8.18 \%$ higher than within the ECA. As expected, the ratio increases with the price of MGO, since it becomes more expensive to maintain a higher speed within ECAs, and so does the average total fuel consumption, as shown by the rightmost column in Table 5 . 


\begin{tabular}{lrcrrrrr} 
& \multicolumn{3}{c}{ Average speed (kn) } & \multicolumn{3}{c}{ Average fuel consumption (tons) } \\
Scenario & $E C A$ & Non-ECA & Ratio & ECA & Non-ECA & Total & Difference \\
\hline C1.1_590 & 16.26 & 16.26 & $0.00 \%$ & 138.2 & 326.5 & 464.7 & - \\
C1.1_920 & 15.40 & 16.66 & $8.18 \%$ & 133.5 & 332.4 & 465.9 & $0.25 \%$ \\
C1.1_960 & 15.37 & 16.68 & $8.55 \%$ & 133.2 & 332.8 & 466.0 & $0.28 \%$ \\
C1.1_1020 & 15.16 & 16.80 & $10.81 \%$ & 132.0 & 335.0 & 466.9 & $0.48 \%$ \\
C1.1_1200 & 15.12 & 16.82 & $11.19 \%$ & 131.8 & 335.4 & 467.2 & $0.53 \%$ \\
\hline
\end{tabular}

Table 5: Average speed and fuel consumption in ECAs and non-ECAs and comparison of total fuel consumption for each scenario with the benchmark (C1.1)

Table 6 shows the fuel costs for the four price scenarios resulting from the optimized speed decisions presented above, next to the estimated fuel costs based on the benchmark speed decisions. The benchmark fuel costs are calculated as if one plans the speeds as no ECAs exists and then impose the cost of the different fuel types (i.e. do not optimize the speed due to the ECAs). The estimated costs within ECAs are calculated using the ECA fuel consumption as given for the benchmark scenario in Table 5 multiplied with the MGO prices in the different scenarios.

\begin{tabular}{lccccccr} 
& \multicolumn{9}{c}{ Optimized fuel costs (USD) } & \multicolumn{3}{c}{ Benchmark fuel costs (USD) } & \\
Scenario & $E C A$ & Non- & Total & ECA & Non-ECA & Total & Savings \\
& & $E C A$ & & & & & \\
\hline C1.1_920 & 122,816 & 196,119 & 318,935 & 127,173 & 192,637 & 319,811 & 876 \\
C1.1_960 & 127,913 & 196,356 & 324,269 & 132,703 & 192,637 & 325,340 & 1,071 \\
C1.1_1020 & 134,611 & 197,637 & 332,248 & 140,997 & 192,637 & 333,634 & 1,386 \\
C1.1_1200 & 158,120 & 197,895 & 356,015 & 165,878 & 192,637 & 358,516 & 2,501 \\
\hline
\end{tabular}

Table 6: Average fuel costs based on optimized speed decisions and based on benchmark decisions, and the cost savings arising from the optimization (C1.1)

From Table 6, we can see that the savings obtained from optimizing the sailing speeds along the given route varies from 876 to 2,501 USD, depending on the price of MGO. This is not very much, but probably enough to make it worthwhile for a shipping company, especially having in mind that this is the saving from sailing only this particular route once, and a shipping company will probably operate this route and similar ones a number of times throughout the year.

Thus far it has been shown that the change in optimal speeds due to the introduction of the ECA regulations leads to slightly higher total fuel consumption. This was also the conclusion from the studies by Psaraftis and Kontovas (2009) and by Doudnikoff and Lacoste (2014). In the following, we also study the impact on the environment. Table 7 shows the total emissions of $\mathrm{CO}_{2}$ and $\mathrm{SO}_{x}$ and the difference between each price scenario and the benchmark. Since $\mathrm{CO}_{2}$ emissions are equal for each fuel, these emissions consequently increase at the same rate as the total fuel consumption. There is a significant decrease in $\mathrm{SO}_{\mathrm{x}}$ emissions, as the large reduction within ECAs 
more than outweighs the minor increase outside. The $\mathrm{SO}_{\mathrm{x}}$ emissions are found to decrease by around $27 \%$ for all scenarios. The ECA regulations are successful in this case with regards to protecting the coastlines from $\mathrm{SO}_{\mathrm{x}}$. However, there will be more $\mathrm{CO}_{2}$ emissions following the ECA regulations, which is harmful for the global environment.

\begin{tabular}{lrrrr}
\multirow{2}{*}{ Scenario } & \multicolumn{2}{c}{$\mathrm{CO}_{2}$ emissions } & \multicolumn{2}{c}{ SO emissions } \\
& Tons & Difference & Kilograms & Difference \\
\hline C1.1_590 & 1473.2 & - & 251.0 & - \\
C1.1_920 & 1476.9 & $0.25 \%$ & 182.2 & $-27.41 \%$ \\
C1.1_960 & 1477.4 & $0.28 \%$ & 182.4 & $-27.33 \%$ \\
C1.1_1020 & 1480.2 & $0.48 \%$ & 183.5 & $-26.87 \%$ \\
C1.1_1200 & 1481.0 & $0.53 \%$ & 183.5 & $-26.87 \%$ \\
\hline
\end{tabular}

Table 7: Average total emissions of $\mathrm{CO}_{2}$ and $\mathrm{SO}_{x}$ and comparisons with benchmark

\subsection{Case analysis C2.1}

Case C2.1 considers a route starting in Bremerhaven in Germany, crossing the Atlantic Ocean after visiting Antwerp and then sailing along the North American east coast from Halifax to Brunswick. The shortest leg between the latter two ports involves a long distance within the ECA. It is therefore appropriate to examine impacts of longer alternatives for this leg, partly outside the ECA. Table 8 gives specific distances for each stretch of the leg options in the route. Only a few promising leg options for the last sailing leg are suggested.

\begin{tabular}{lcrrr} 
Leg & Leg option & \multicolumn{3}{c}{ Distance } \\
& & ECA & Non-ECA & Total \\
\hline Bremerhaven - Antwerp & - & 306 & 0 & 306 \\
\hline Antwerp - Halifax & - & 772 & 2,101 & 2,873 \\
\hline & 1 & 1,186 & 0 & 1,186 \\
& 2 & 514 & 831 & 1,345 \\
Halifax - Brunswick & 3 & 476 & 890 & 1,366 \\
& 4 & 445 & 987 & 1,432 \\
& 5 & 879 & 352 & 1,231 \\
\hline
\end{tabular}

Table 8: Distances of route leg options in nautical miles (C2.1)

The five alternative sailing legs between Halifax and Brunswick for case C2.1 are shown in Figure 8, together with the line illustrating the border of the ECA. Leg option 1 is the shortest leg, going in nearly a straight line between the ports, entirely within the ECA. Leg option 4 is the leg with the minimal ECA distance, but also the longest in total. 


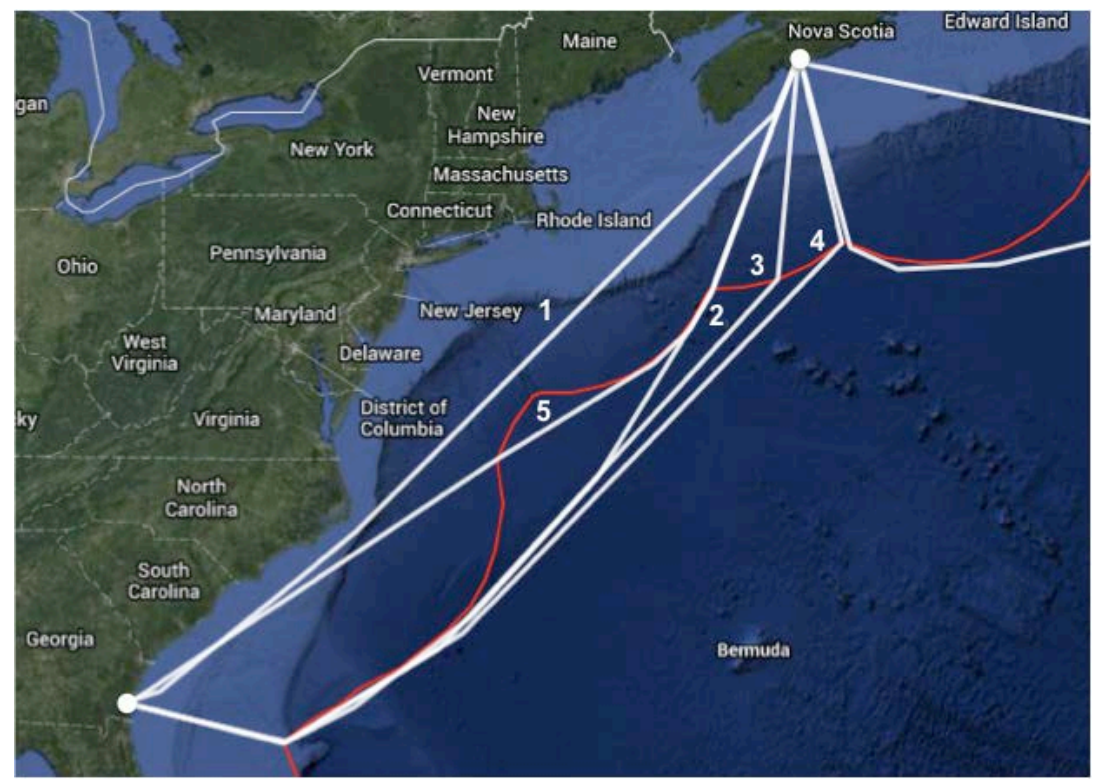

Figure 8: Map of alternative leg options between Halifax and Brunswick (C2.1)

The optimal average speed within each area is presented in Table 9 for the various price scenarios next to the speed ratio between the non-ECA speed and the ECA speed. The results for each price scenario are average values over five different time window widths, ranging from 1 to 5 days, generated as described in Section 3.3. As seen from the table, the speed outside ECAs is approximately $6.6 \%$ higher than the speed within ECAs for MGO prices of 920 USD/ton. However, more important are the changes in sailing distances due to the ECA regulations. The optimal distances are also given in Table 9, and the ratio gives the difference between the non-ECA and the ECA distance. This ratio increases as the MGO price increases, and so does the total distance. For the standard scenario (MGO price of 920), the ECA distance is reduced by over $20 \%$ compared to the benchmark, while the non-ECA stretches become over $26 \%$ longer. The total distance increases by $2.2 \%$.

\begin{tabular}{lrcrrrrr} 
Scenario & \multicolumn{3}{c}{ Average speed } & \multicolumn{3}{c}{ Average distances } \\
& ECA & Non-ECA & Ratio & ECA & Non-ECA & Total & Ratio \\
\hline C2.1_590 & 15.7 & 15.7 & $0.00 \%$ & 2,264 & 2,101 & 4,365 & $-7.20 \%$ \\
C2.1_920 & 15.3 & 16.3 & $6.62 \%$ & 1,803 & 2,656 & 4,460 & $47.30 \%$ \\
C2.1_1020 & 15.2 & 16.6 & $9.50 \%$ & 1,584 & 2,944 & 4,528 & $85.80 \%$ \\
C2.1_1200 & 15.2 & 16.7 & $9.63 \%$ & 1,577 & 2,956 & 4,532 & $87.44 \%$ \\
C2.1_2000 & 15.0 & 17.2 & $14.75 \%$ & 1,504 & 3,115 & 4,619 & $107.05 \%$ \\
\hline
\end{tabular}

Table 9: Average speed (knots) and distances (nautical miles), and ratio between non-ECA and ECA measures (C2.1)

Average numbers for the fuel consumption are given for the same scenarios in Table 10 along with comparisons between each scenario and the benchmark. There is a clear trend for all the results, where ECA consumption falls compensated by increases outside. For the standard scenario, the consumption within ECAs is 
reduced by $21.75 \%$ compared to the benchmark, with an associated increase in nonECA consumption (i.e. HFO) of $30.01 \%$. The relatively larger increase outside ECAs results in $3.17 \%$ higher total fuel consumption. This is a substantial difference, equal to 21 tons of fuel for one trip along the route.

\begin{tabular}{lrrrrrr} 
Scenario & \multicolumn{6}{c}{ Average fuel consumption (tons) } \\
& ECA & Difference & Non-ECA & Difference & Total & Difference \\
\hline C2.1_590 & 344.1 & - & 319.5 & - & 663.6 & - \\
C2.1_920 & 269.3 & $-21.75 \%$ & 415.3 & $30.01 \%$ & 684.6 & $3.17 \%$ \\
C2.1_1020 & 235.4 & $-31.59 \%$ & 471.1 & $47.47 \%$ & 706.5 & $6.47 \%$ \\
C2.1_1200 & 234.3 & $-31.92 \%$ & 473.3 & $48.16 \%$ & 707.6 & $6.63 \%$ \\
C2.1_2000 & 221.4 & $-35.65 \%$ & 512.9 & $60.55 \%$ & 734.3 & $10.66 \%$ \\
\hline
\end{tabular}

Table 10: Average fuel consumption in each area and comparison of each scenario with the benchmark (C2.1)

Table 11 shows the optimized fuel costs for each price scenario based on the new sailing leg and speed decisions, and the fuel costs based on benchmark decisions for the corresponding MGO prices. Now, more than USD 12,000 can saved per voyage from making new and optimal decisions for the standard scenario compared to maintaining the benchmark operations when ECAs are enforced. The numbers are large, comprising $2.5 \%$ of the total costs for the standard scenario, and more than 7\% for C2.1_1200, which reflects a higher but still realistic MGO price. If a shipping company for example controlled five similar vessels sailing this route once a month each, the total annual saving for the standard scenario would be USD 736,560, and USD 1,284,000 for C2.1_1020. These numbers illustrate the great cost impacts, which also make it clear that shipping companies actually will adapt to the ECA regulations by optimizing both the speeds and the sailing paths between ports.

\begin{tabular}{lccccccr}
\multirow{2}{*}{ Scenario } & \multicolumn{3}{c}{ Optimized fuel costs (USD) } & \multicolumn{6}{c}{ Benchmark fuel costs (USD) } & \multirow{2}{*}{ Savings } \\
& ECA & Non-ECA & Total & ECA & Non-ECA & Total & \\
\hline C2.1_920 & 247,723 & 245,043 & 492,766 & 316,561 & 188,480 & 505,042 & 12,276 \\
C2.1_1020 & 240,097 & 277,954 & 518,051 & 350,970 & 188,480 & 539,450 & 21,400 \\
C2.1_1200 & 281,124 & 279,248 & 560,373 & 412,906 & 188,480 & 601,386 & 41,014 \\
C2.1_2000 & 442,876 & 302,596 & 745,472 & 688,176 & 188,480 & 876,657 & 131,185 \\
\hline
\end{tabular}

Table 11: Average fuel costs based on optimized speed and leg decisions and based on benchmark decisions, and the cost saving arising from the optimization (C2.1)

The average total emissions of $\mathrm{CO}_{2}$ and $\mathrm{SO}_{\mathrm{x}}$ are given in Table 12 together with the difference between each scenario and the benchmark. These numbers represent one trip along the given route with the chosen leg options, and for one such voyage with the standard scenario, more than 66 tons of additional $\mathrm{CO}_{2}$ is produced when ECA regulations are enforced, corresponding to an increase of $3.17 \%$. For relatively small MGO price increases to 970 and $1,020 \mathrm{USD} /$ ton, $5.08 \%$ and $6.47 \%$ more $\mathrm{CO}_{2}$ is 
emitted, respectively. The percentage increase in $\mathrm{CO}_{2}$ emissions is equal to that of the total fuel consumption.

\begin{tabular}{lrrrr}
\multirow{2}{*}{ Scenario } & \multicolumn{2}{c}{$\mathrm{CO}_{2}$ emissions } & \multicolumn{2}{c}{ SO emissions emis } \\
& Tons & Difference & Kilograms & Difference \\
\hline C2.1_590 & $2,103.4$ & - & 358.3 & - \\
C2.1_920 & $2,170.2$ & $3.17 \%$ & 229.7 & $-35.91 \%$ \\
C2.1_1020 & $2,239.6$ & $6.47 \%$ & 259.1 & $-27.69 \%$ \\
C2.1_1200 & $2,243.0$ & $6.63 \%$ & 260.3 & $-27.36 \%$ \\
C2.1_2000 & $2,327.8$ & $10.66 \%$ & 281.4 & $-21.47 \%$ \\
\hline
\end{tabular}

Table 12: Average total emissions of $\mathrm{CO}_{2}$ and $\mathrm{SO}_{x}$ and comparisons with benchmark (C2.1)

The magnitude of $\mathrm{SO}_{\mathrm{x}}$ emissions is different with lower absolute values, but the damage caused by $\mathrm{SO}_{x}$ can regardless be severe. The sulphur limits within ECAs combined with lower speed and shorter distances lead to a reduction in $\mathrm{SO}_{\mathrm{x}}$ in these areas of $70 \%$. Outside ECAs however, the emissions increase by around $30 \%$ for the most relevant prices. The overall consequence is a reduction of around $35 \%$. Since $\mathrm{SO}_{\mathrm{X}}$ is considered more damaging in coastal areas due to the close presence of humans and living species, the regulations are undoubtedly successful in their attempt to provide cleaner air in those regions. The effects of lower speed and new sailing legs work in the same direction as the direct reduction effects within ECAs.

\subsection{Case analysis C2.2}

Case C2.2 examines south-going routes from different ports along the Norwegian coast in order to analyze at which point it is profitable to sail around the UK instead of sailing within the ECA through the North Sea and the English Channel. Five ports are considered, located in the south and west of Norway. The distances are given in nautical miles in Table 13. From Kristiansand (the southernmost port in Norway) to Santander there are two leg options, where the longer option involves sailing out of the ECA at the western border just north of Scotland. For the other four cases this is an alternative as well, but an additional leg involves exiting the ECA at the northern border outside the west coast of Norway. 


\begin{tabular}{llcrrr} 
Case & Leg & Leg option & & Distance \\
& & & ECA & Non-ECA & Total \\
\hline 2.2a & Kristiansand - Santander & 1 & 761 & 360 & 1,121 \\
& & 2 & 395 & 1,025 & 1,420 \\
\hline 2.2b & Flekkefjord - Santander & 1 & 760 & 361 & 1,121 \\
& & 2 & 340 & 1,030 & 1,370 \\
& & 3 & 275 & 1,400 & 1,675 \\
\hline 2.2c & Stavanger-Santander & 1 & 790 & 362 & 1,152 \\
& & 2 & 310 & 1,065 & 1,375 \\
& & 3 & 230 & 1,430 & 1,660 \\
\hline 2.2d & Bergen - Santander & 1 & 872 & 365 & 1,237 \\
& & 2 & 277 & 1,020 & 1,297 \\
& & 3 & 120 & 1,420 & 1,540 \\
\hline 2.2e & Flor $\varnothing-S a n t a n d e r$ & 1 & 927 & 365 & 1,292 \\
& & 2 & 307 & 1,022 & 1,329 \\
& & 3 & 34 & 1,425 & 1,459 \\
\hline
\end{tabular}

Table 13: Distances of route leg options in nautical miles (C2.2)

All the different legs are illustrated in Figure 9 below, with the circles representing the different ports.

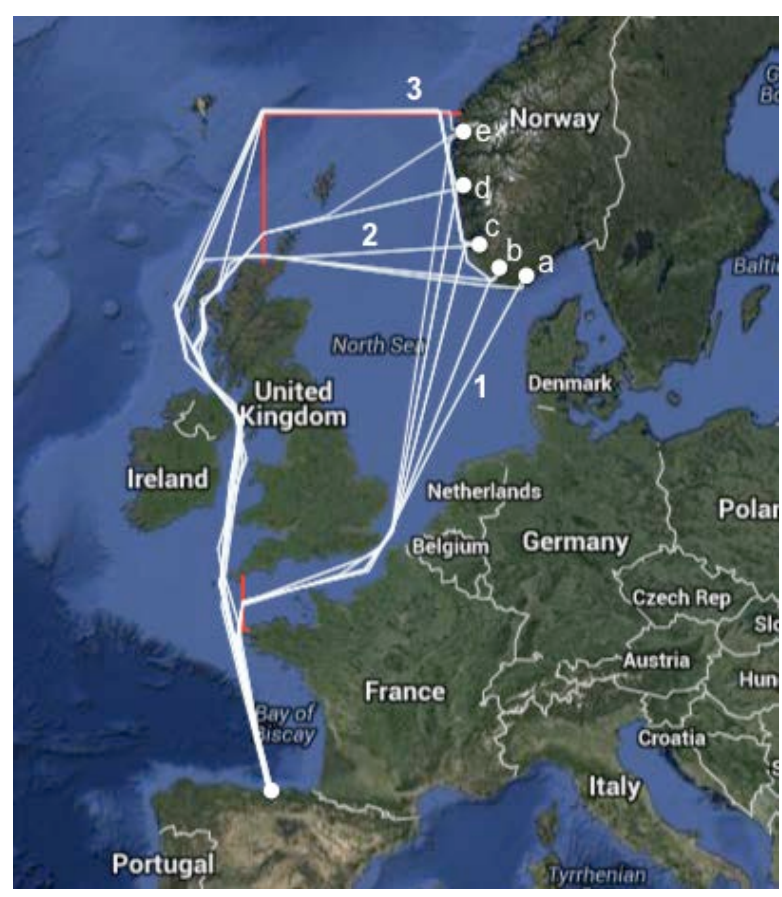

Figure 9: Map of alternative leg options between different Norwegian ports and Santander (C2.2)

The shortest leg within the ECA is chosen between Kristiansand and Santander (Case 2.2a) for all MGO prices below 1,600 USD/ton, which is a higher price than probable. The same holds for the leg starting in Flekkefjord (Case 2.2b), where the MGO price 
must reach 1,420 before a change to leg option 2 occurs. These two case variations will therefore not be analyzed further.

The distance and speed within each area are given for the legs from Stavanger (C2.2c), Bergen (C2.2d) and Florø (C2.2e) in Table 14 for the benchmark and standard scenarios, along with the ratios between the non-ECA and ECA. The results for each price scenario are average values over six different time window widths, ranging from 0.5 to 3 days, generated as described in Section 3.3. The speed is $3.6-3.8 \%$ higher outside ECAs than within in all cases. The largest increase in total distance, of $6.6 \%$, appears for the leg from Stavanger, even though the longer option is only chosen for two out of six time situations. This is because there is a larger difference between the total distances of the leg options than for the other two cases. The ratio on the other hand changes by much more for the other two cases.

\begin{tabular}{lrcrrrrr} 
Scenario & \multicolumn{3}{c}{ Average speed } & \multicolumn{4}{c}{ Average distances } \\
& $E C A$ & Non-ECA & Ratio & ECA & Non-ECA & Total & Ratio \\
\hline C2.3c_590 & 15.44 & 15.44 & $0.00 \%$ & 783 & 363 & 1,146 & $46.36 \%$ \\
C2.3c_920 & 15.27 & 15.84 & $3.64 \%$ & 625 & 597 & 1,222 & $95.52 \%$ \\
\hline C2.3d_590 & 15.49 & 15.49 & $0.00 \%$ & 872 & 365 & 1,237 & $41.86 \%$ \\
C2.3d_920 & 15.36 & 15.96 & $3.79 \%$ & 277 & 1,020 & 1,297 & $368.23 \%$ \\
\hline C2.3e_590 & 15.52 & 15.52 & $0.00 \%$ & 927 & 365 & 1,292 & $39.37 \%$ \\
C2.3e_920 & 15.28 & 15.86 & $3.73 \%$ & 216 & 1,156 & 1,372 & $535.19 \%$ \\
\hline
\end{tabular}

Table 14: Average speed (knots) and distances (nautical miles), and ratio between non-ECA and ECA measures for Stavanger (c), Bergen (d) and Florø (e) (C2.2)

The average fuel consumed when sailing the given legs is presented in Table 15 for the same three case variations and scenarios. The leg from Florø (Case 2.2e) is the longest and at the same time the one most suited for changes. For the standard scenario, this case consequently gives the largest reduction in ECA consumption, but also the largest increase outside the ECA and in total. The difference in total consumption compared to the benchmark is around 7\% for all cases (and so is the increase in $\mathrm{CO}_{2}$ emissions). This increase is substantial, here corresponding to 12 to 15 tons per voyage. 
Scenario Average fuel consumption (tons)

\begin{tabular}{lrrrrrr} 
& ECA & Difference & Non-ECA & Difference & Total & Difference \\
\hline C2.3c_590 & 117.8 & - & 54.6 & - & 172.4 & - \\
C2.3c_920 & 93.6 & $-20.51 \%$ & 90.3 & $65.40 \%$ & 183.9 & $6.70 \%$ \\
\hline C2.3d_590 & 131.5 & - & 55.0 & - & 186.5 & - \\
C2.3d_920 & 41.5 & $-68.43 \%$ & 157.8 & $186.62 \%$ & 199.3 & $6.83 \%$ \\
\hline C2.3e_590 & 140.0 & - & 55.1 & - & 195.1 & - \\
C2.3e_920 & 32.4 & $-76.84 \%$ & 177.0 & $221.11 \%$ & 209.4 & $7.33 \%$ \\
\hline
\end{tabular}

Table 15: Average fuel consumption in each area and comparison of each scenario with the benchmark for Stavanger (c), Bergen (d) and Florø (e) (C2.2)

Fuel costs are shown in Table 16 for the optimized decisions given above and for the benchmark solutions with new fuel costs, given for the standard scenarios. In this case, the majority of the savings from new decisions originate in the changed sailing legs. This is because altering the speed alone would not have the potential to change the overall outcome by much considering the ECA distance is longer than the nonECA distance for the shortest legs. From Stavanger (C2.2c), the fuel costs decrease by $0.82 \%$ from optimizing the speed and the sailing path, corresponding to a saving of USD 1,156 . This is noteworthy, but not nearly as high as the other cases since the longer leg is only chosen for certain time situations from Stavanger. The impact of the changed sailing legs is extensive for the legs from Bergen and Florø. For Bergen (C2.2d), the fuel cost is reduced by $14.45 \%$ from the optimization. This corresponds to a cost saving of USD 22,175 compared to keeping the constant benchmark speed going the shortest leg. Similarly for Flor $\varnothing$ (C2.2e), the reduction totals $16.77 \%$ and a cost saving of USD 27,052 . These numbers are of great importance. If a ship operator serviced 50 such voyages during a year, the cost difference would be more than USD 1.3 million, which is remarkable.

\begin{tabular}{lrrrrrrr}
\multirow{2}{*}{ Scenario } & \multicolumn{2}{c}{ Optimized fuel costs (USD) } & \multicolumn{3}{c}{ Benchmark fuel costs (USD) } & \multirow{2}{*}{ Saving } \\
& \multicolumn{1}{c}{ ECA } & Non-ECA & \multicolumn{1}{c}{ Total } & \multicolumn{1}{c}{ ECA } & Non-ECA & Total & \\
\hline C2.2c_920 & 86,120 & 53,279 & 139,399 & 108,343 & 32,211 & 140,555 & 1,156 \\
C2.2d_920 & 38,195 & 92,073 & 131,267 & 120,970 & 32,473 & 153,442 & 22,175 \\
C2.2e_920 & 29,826 & 104,416 & 134,242 & 128,777 & 32,517 & 161,295 & 27,052 \\
\hline
\end{tabular}

Table 16: Average fuel costs based on optimized speed and leg decisions and based on benchmark decisions, and the cost saving arising from the optimization (C2.2 c-e)

\subsection{Case analysis C2.3}

It has been up for discussion in the IMO to designate the Mediterranean Sea as an ECA. This was also considered by Panagakos et al. (2014), who showed that shifts to the road mode may be expected as a consequence of this. In case C2.3 we analyze some possible effects on the sailing distance and fuel consumption from designating the Mediterranean Sea as an ECA. This means that the low-sulphur fuel MGO must 
be used in the entire area enclosed by northern Africa and southern Europe. Many shipping companies currently sail from Southeast Asia to Europe through the Mediterranean Sea. We consider a voyage from Cilacap, Indonesia, to Southampton in Europe. Two alternative sailing leg options have been defined, the second one going around Africa in the south instead of crossing through the Mediterranean Sea as the first sailing leg option. The distances for the legs are given in Table 17.

\begin{tabular}{|c|c|c|c|c|c|}
\hline \multirow{2}{*}{ Case } & \multirow{2}{*}{ Leg } & \multirow{2}{*}{ Leg option } & \multicolumn{3}{|c|}{ Distance } \\
\hline & & & $E C A$ & Non-ECA & Total \\
\hline \multirow{2}{*}{2.3} & \multirow{2}{*}{ Cilacap - Southampton } & 1 & 2,140 & 6,429 & 8,569 \\
\hline & & 2 & 180 & 11,045 & 11,225 \\
\hline
\end{tabular}

Table 17: Distances of route leg options in nautical miles (C2.3)

The difference in distances for the two proposed legs is substantial. Almost 2,000 nautical miles within the ECA can be avoided, but the increase outside is much larger, resulting in a considerably longer total distance. However, there is another aspect that should be taken into account for this problem. Ships have to pay a high fee to sail through the Suez Canal. This fee is added to the objective function when the ship sails along leg option 1 . Thus, the new objective function is expanded to include this.

The results from C2.3 show that leg option 1, through the Mediterranean Sea, would still often be chosen, but it depends largely on time flexibility. However, in the situations where the time windows allow a longer sailing, it may be optimal to use sailing leg option 2 south of Africa. Table 18 shows the optimal sailing leg and speed for three different time duration limits, the second leg option is chosen for the widest time window. This situation is denoted by TL_5 and indicates that the ship is allowed to sail for five days more than the sailing time at reference speed, which is quite common nowadays where slow-steaming is widely used. The speed is increased by $13.3 \%$ within ECAs and $26.6 \%$ outside when the time range increases from four to five days and the leg decision is altered. This is due to an increase in the total distance by almost 3,000 nautical miles, which has to be sailed using only slightly more time. 


\begin{tabular}{lcrrrrr}
\multirow{2}{*}{ Situation } & Chosen leg & \multicolumn{2}{c}{ Distance (nautical miles) } & \multicolumn{2}{c}{ Speed (knots) } \\
& option & $E C A$ & Non-ECA & Total & ECA & Non-ECA \\
\hline C2.3_920_TL_3 & 1 & 2,140 & 6,429 & 8,569 & 15.00 & 16.57 \\
C2.3_920_TL_4 & 1 & 2,140 & 6,429 & 8,569 & 15.00 & 15.61 \\
C2.3_920_TL_5 & 2 & 180 & 11,225 & 11,405 & 17.00 & 19.76 \\
\hline
\end{tabular}

Table 18: Chosen leg option with corresponding distances and speed decisions in each area for different time window situations for the standard scenario (C2.3)

The situation using the sailing leg option 2 for C2.3_920_TL_5 gives an increase in total fuel consumption of as much $71 \%$, and thus a similar increase in $\mathrm{CO}_{2}$ emissions. In this case the total $\mathrm{SO}_{\mathrm{x}}$ emissions will actually also increase by as much $69 \%$, which clearly would be a counterproductive effect of the ECA regulations.

\section{CONCLUDING REMARKS}

Fuel costs have become an important cost item in shipping, sometimes accounting for more than $50 \%$ of the total operational costs. Strict limits on the maximum sulphur content in fuel used by ships have recently been imposed by MARPOL in some Emission Control Areas (ECAs). In order to comply with these regulations many ship operators will need to switch to low-sulphur fuel (e.g. Marine Gas Oil (MGO)) when sailing inside ECAs. Low-sulphur fuel is more expensive than normal Heavy Fuel Oil (HFO), which can be used outside the ECAs, and the new ECA regulations will therefore impact international shipping in several ways.

In this paper, we have proposed an optimization model to be applied by ship operators in the case of ECAs for determining sailing paths and speeds that minimize operating costs for a ship along a given sequence of ports. In order to examine the implications for the society with regards to environmental effects, we have performed a computational study on a number of realistic shipping routes. It has been shown that a likely effect of the regulations is that ship operators in many situations will choose to sail longer distances to avoid or reduce the sailing within the ECAs. Another effect is that they will sail at lower speeds within and higher speeds outside the ECAs in order to use less of the more expensive fuel. On some shipping routes, this might give a considerable increase in the total amount of fuel used and hence the $\mathrm{CO}_{2}$ emissions. In some rare situations the consequence of the ECA regulations may even be that the $\mathrm{SO}_{\mathrm{x}}$ emissions increase because it might be profitable to choose much longer sailing paths to avoid the ECAs. This effect will depend on the price difference between MGO and HFO and become stronger if MGO becomes more expensive compared to HFO. 
From a policy perspective, we believe that no general conclusions on ECA effectiveness can be drawn from this paper alone. However, the paper demonstrates that ship owners can react in ways that may limit ECA's effectiveness. If the ECAs were to be redesigned, it would, given the results presented in this paper, make sense to use models similar to what we have developed in this paper, as part of the regulators' decision support and what-if analysis of policy alternatives. However, existing ECAs in Europe and North America have been designed in an ad hoc fashion and are not likely to be modified any time soon. This may only be possible for future ECAs in other parts of the world, for instance the Mediterranean. So long as there is a different regime within an ECA and outside an ECA, owners will be free to select route and speed to optimize their operation. Of course, a significant difference between regulators and shipping operators is that the regulators' decision is strategic whereas the operator's decision is operational. Regulators thus far have been unable (for various reasons) to anticipate the possible side-effects of their decisions, including how shipping may react to them. Side-effects include not only avoiding ECAs to minimize costs, but possible shifts of cargo to land-based modes, to the extent these are alternatives to waterborne transport. The situation in the Baltic and North Sea, with the application of the $0.1 \%$ sulphur limit as from 2015 is a prime example. Many feel that this will cause significant cost increases to the shipping industry, to shippers and to the industry at large, as is documented in several studies and by the reaction of the industry.

Last but not least, to draw general conclusions on whether the ECA concept is costeffective, one has to look at the wider picture. In many ways it is a difficult question, on which the jury is still out. The main benefit of ECAs is supposed to be reduced $\mathrm{SO}_{\mathrm{x}}$ (and $\mathrm{NO}_{\mathrm{x}}$ in North America) within the ECAs. Even though the global extent of these reductions is not yet known, our analyses show that the ECAs are effective in reducing these emissions (except for a few rare situations). However, this may come at the expense of increase $\mathrm{CO}_{2}$ emissions. Due to the nature of the regulatory process, side effects such as this, along with several others, have not been addressed by regulators whose main primary objective is to reduce $\mathrm{SO}_{\mathrm{x}}$ emissions. A fortiori, questions concerning what would be the overall societal costs are at this point open. As the ECA concept is a regional policy, one should be careful that it does not create distortions that may make difficult to maintain a level playing field among shipping operators. We believe that the work reported in this paper can shed some light on how the shipping industry may behave in an ECA regime.

\section{ACKNOWLEDGEMENTS}

This research was carried out with financial support from the GREENSHIPRISK project, partly funded by the Research Council of Norway. The work of H. Psaraftis 
was supported by the Danish Maritime Cluster project (2011-2014), financed by the European Social Fund and the Capital Region of Denmark (Growth Fund). Thanks are due to the referee for valuable comments.

\section{REFERENCES}

Andersson, H., Fagerholt, K. and Hobbesland, K., 2015. Integrated maritime fleet deployment and speed optimization: Case study from RoRo shipping. Computers \& Operations Research 55, 233-240.

Balland, O., Erikstad, S. and Fagerholt, K., 2012. Optimized selection of air emission controls for vessels. Maritime Policy \& Management 39(4), 387-400.

Balland, O., Erikstad, S., Fagerholt, K. and Wallace, S., 2013. Planning vessel air emission regulations compliance under uncertainty. Journal of Marine Science and Technology 18(3), 349-357.

Brynolf, S., Magnusson, M., Fridell, E. and Andersson, K., 2014. Compliance possibilities for the future ECA regulations through the use of abatement technologies or change of fuels. Transportation Research Part D: Transport and Environment 28, 6-18.

Cullinane, K. and Bergqvist, R., 2014. Emission control areas and their impact on maritime transport. Transportation Research Part D: Transport and Environment 28, $1-5$.

Doudnikoff, M. and Lacoste, R., 2014. Effect of a speed reduction of containerships in response to higher energy costs in Sulphur Emission Control Areas. Transportation Research Part D: Transport and Environment 27, 19-29.

Fagerholt, K., Laporte, G. and Norstad, I., 2010. Reducing fuel emissions by optimizing speed on shipping routes. Journal of the Operational Research Society 61(3), 523-529.

Hvattum, L. M., Norstad, I., Fagerholt, K. and Laporte, G., 2014. Analysis of an exact algorithm for the vessel speed optimization problem. Networks 62(2), 132-135.

IMO, 2014. International Maritime Organization websites. Available from: <http://www.imo.org/OurWork/Environment/PollutionPrevention/AirPollution/Page s/Air-Pollution.aspx>. [accessed 30.03.2014]

Jiang, L., Kronbak, J. and Christensen, L., 2014. The costs and benefits of sulphur reduction measures: Sulphur scrubbers versus marine gas oil. Transportation Research Part D: Transport and Environment 28, 19-27. 
Norstad, I., Fagerholt, K. and Laporte, G., 2011. Tramp ship routing and scheduling with speed optimization. Transportation Research Part C: Emerging Technologies 19, 853-865.

Panagakos, G., Stamatopoulou, I.V. and Psaraftis, H.N., 2014. The Possible Designation of the Mediterranean as a SECA: a Case Study. Transportation Research Part D: Transport and Environment 28, 74-90.

Psaraftis, H.N. and Kontovas, C.A., 2009. Ship Emissions: Logistics and Other Tradeoffs. 10th International Marine Design Conference (IMDC), Trondheim, Norway, 26-29 May 2009.

Psaraftis, H. and Kontovas, C., 2013. Speed models for energy-efficient maritime transportation: A taxonomy and survey. Transportation Research Part C: Emerging Technologies 26, 331-351.

Schinas, O. and Stefanakos, C.N., 2012. Cost assessment of environmental regulation and options for marine operators. Transportation Research Part C: Emerging Technologies 25, 81-99.

Wang, S., Meng, Q. and Liu, Z., 2013. Bunker consumption optimization methods in shipping: A critical review and extensions. Transportation Research Part E: Logistics and transportation Review 53, 49-62.

Yang, Z., Zhang, D., Caglayan, O., Jankinson, I., Bonsall, S., Wang, J., Huang, M. and Yan, X., 2012. Selection of techniques for reducing shipping NOx and SOx emissions. Transportation Research Part D: Transport and Environment 17, 478-486. 